\title{
New performance-evaluation analyses on heat transfer surfaces by single-blow technique
}

\author{
YOON S. SIM \\ Thermal-Fydraulic Design Department, Korea Advanced Energy Research Institute, P.O. Box 7 , \\ Daeduck Danji, Chungnam, Korea 300-31 \\ and \\ WEN-JEI YANG \\ Department of Mechanical Engineering and Applied Mechanics, University of Michigan, Ann Arbor, \\ MI 48109, U.S.A.
}

(Received 29 October 1985 and fonal form 15 September 1986)

\begin{abstract}
This paper presents a method which can consider the space dependence of the heat transfer coefficient of heat exchanger units or surfaces in evaluating heat transfer performance of a system by a single-blow technique. The performance-evaluation analysis is conducted in the Laplace transformed domain. Cubic spline polynomials are employed to fit the measured inlet and exit fluid temperatures. Also the conventional analysis method is improved through a modified mathematical modelling for a better accuracy. The methods are applied to evaluate the heat transfer performance in stationary and rotating parallel-disk assemblies.
\end{abstract}

\section{INTRODUCTION}

STEADY state and transient state methods have been employed to determine the heat transfer coefficient between the transfer surface or matrix in the heat exchanger and the flowing fluid [1]. The former keeps the system steady with a constant heat source, while the latter introduces a perturbation to the system and observes the response of the system to the perturbation. Generally the analysis of a transient method is more complicated than that of a steady method and also requires more assumptions. The additional assumptions in a transient method may render less accurate evaluation and it can be a weak point of a transient method. A transient method, however, requites much less time, effort and money than a steady state method. This is the main advantage of a transient method and is the reason for its wide use. Also there are some systems where a steady state method is virtually not applicable and a transient method should be used such as the systems indicated in ref. [2]. A brief survey on the literature pertinent to performance test methods is presented in ref. [1] and thus will not be repeated here.

The assumptions in the transient methods may not be fully validated in practice. Then, those assumptions come to work as the source of the less accurate evaluation. In this paper, some of the required assumptions of the conventional transient methods are removed through improved mathematical modelling for a better accuracy.

In the transient method case, the outlet fluid temperature varies with time as the inlet temperature and convective heat transfer become time dependent. It results in timewise changes in the enthalpies of both the surface and the fluid in the system. Its solution is then matched with the measured exit fluid temperature response curve to determine the heat transfer coefficient. A heating screen installed upstream of the test core is commonly utilized as a heat source.

Two typical time functions of the inlet fuid temperature $T_{\text {in }}(t)$ have been employed : a stepwise change and a sinusoidal change in $T_{\mathrm{in}}(l)$ for transient response and frequency response methods, respectively. The former is commonly employed [1,3-14]. Schumann [3] obtained the analytical solution for the outlet fluid temperature $T_{t}(t)$ in response to a step change in the inlet fiuid temperature. His solution was improved by Kohimayr [8], who analytically solved the single-blow problem by means of a double Laplace transform method. He named the solution the response function, the properties of which were examined in ref. [10]. The response function to an arbitrary inlet fiuid temperature change was obtained in ref. [11]. The centroid method was developed for indirect curve matching of the measured and analytical temperature response curves.

In response to an on-or-off operation of the heating element, conventional data reduction is used to determine $\bar{h}$, using the maximum slope of the exit fluid temperature curve $T_{\mathrm{e}}(t)$. The approach is commonly called the maximum slope method $[4,5,7,9]$. Mondt and Siegla [6] correlated the initial fractional step rise in $T_{e}$ at zero time with Schumann's solution. This procedure is referred to as the initial rise method. Liang and Yang [12] determined $\bar{h}$ by matching the 


\section{NOMENCLATURE}

$a_{\mathrm{f}}, b_{\mathrm{f}}, b_{\mathrm{s}}$ parameters defined by equation (7)

$a_{i}, b_{i}, c_{i}, d_{i}$ coefficients defined by equation

(12)

$B \quad$ disk spacing [m]

$b$ disk thickness [m]

$c \quad$ specific heat $\left[\mathrm{J} \mathrm{kg}^{-1} \mathrm{~K}^{-1}\right] ; c_{\mathrm{f}}$, of fluid ; $c_{\mathrm{s}}$, of disk wall

$E \quad$ parameter defined by equation (11)

$F_{i}^{(\prime)} \quad$ function defined by equation (16)

$g$ scale factor in local heat transfer coefficient as defined by equation (17)

$h \quad$ heat transfer coefficient $\left[\mathrm{W} \mathrm{m}^{-2} \mathrm{~K}^{-1}\right] ; \bar{h}$, average value; $h^{*}$, best-fit value of $h$;

$h_{\mathrm{N}}$, distribution of $h$

$I \quad$ modified Bessel function of the first kind

$k$ thermal conductivity [W $\left.\mathrm{m}^{-1} \mathrm{~K}^{-1}\right] ; k_{\mathrm{f}}$, of fluid ; $k_{\mathrm{s}}$, of wall

$M(\tau)$ function defined by equation (9)

$N u \quad$ Nusselt number, $h B / k_{\mathrm{f}} ; \overline{N u}=\bar{h} B / k_{\mathrm{f}}$

$p \quad$ Laplace variable $\left[\mathrm{s}^{-1}\right] ; p_{\mathrm{H}}$, upper limit of $p ; p_{\mathrm{L}}$, lower limit of $p$

Re Reynolds number, $u_{\mathrm{in}} B / v$

$R_{t} \quad$ rotation number, $r_{\mathrm{in}} \Omega / u_{\mathrm{in}}$

$r \quad$ radial coordinate $[\mathrm{m}] ; r_{\mathrm{e}}$, outside radius of disk; $r_{\text {in }}$, inside radius of disk

$S_{i} \quad$ coefficient defined by equation (13)

$T \quad$ temperature $[\mathrm{K}] ; T_{c}$, of fluid calculated; $T_{\mathrm{e}}$, of fluid at exit; $T_{\mathrm{f}}$, of fluid; $T_{\mathrm{in}}$, of fluid at inlet; $T_{0}$, at initial state; $T_{s}$, of disk wall; $T_{\mathrm{m}}$, of fluid measured

$\bar{T} \quad$ Laplace-transformed temperature; $\bar{T}_{\mathrm{e}}$, of fluid at exit; $\bar{T}_{\mathrm{f}}$, of fluid; $\bar{T}_{\text {in }}$, of fluid at inlet; $\bar{T}_{\mathrm{s}}$, of disk wall

$t \quad$ time [s] $; t_{\mathrm{L} p}$ and $t_{\mathrm{H} p}$, upper and lower time limits, respectively, in Laplace-domain analysis ; $t_{\mathrm{H} t}$ and $t_{\mathrm{L} t}$, upper and lower time limits, respectively in time-domain analysis $; t^{*}=x_{\mathrm{e}} / a_{\mathrm{f}}$

$u$ flow velocity $\left[\mathrm{m} \mathrm{s}^{-1}\right] ; u_{\text {in }}$, at inlet

$w \quad \exp (-p t) ; w_{\mathrm{H}}$, upper limit of $w ; w_{\mathrm{L}}$, lower limit of $w$

$x \quad \pi\left(r^{2}-r_{\text {in }}^{2}\right)\left[\mathrm{m}^{2}\right] ; x_{\mathrm{e}}$, at exit

$z \quad$ axial coordinate $[\mathrm{m}]$.

\section{Greek symbols}

$\varepsilon \quad$ error

$\theta \quad$ angular coordinate [rad]

$\nu \quad$ kinematic viscosily $\left[\mathrm{m}^{2} \mathrm{~s}^{-1}\right]$

$\rho \quad$ density $\left[\mathrm{kg} \mathrm{m}^{-3}\right] ; \rho_{\mathrm{l}}$, of fluid ; $\rho_{\mathrm{s}}$, disk wall

$\tau \quad$ dummy variable

$\Omega \quad$ angular velocity of rotating disks $\left[\mathrm{rad} \mathrm{s}{ }^{-1}\right.$.

\section{Subscripts}

c valuc obtained by calculation

e at exit

ep extrapolation

f fluid

H upper limit

$i$ integer

in at inlet

L lower limit

$\mathrm{m} \quad$ value obtained by measurement

$0 \quad$ initial state (reference value)

$p \quad$ Laplace-domain analysis

s disk wall

$t$ time-domain analysis.

\section{Superscripts}

$j \quad$ integer

* best-fit value or dummy. measured curve with the theoretical solution for $T_{\mathrm{e}}(t)$ in response to an exponential function of $T_{\text {in }}(t)$.

The conventional means of performance evaluation have been analyzed in the time domain [1, 3-14]. It is to determine the average heat transfer coefficient in the entire test core by matching the theoretical and measured exit fluid temperature response curves. However, when $T_{\mathrm{e}}(t)$ responds with a time delay at small times and a steady increase at large times, as shown in Fig. 1, neither the maximum slope nor the initial fractional step rise at zero time can adequately characterize such a $T_{\mathrm{e}}(t)$ curve. Since the entire measured $T_{\mathrm{e}}(t)$ curve must be fed into the theoretical calculation, a more sophisticated form of describing the curve is desired for higher accuracy in the final result.

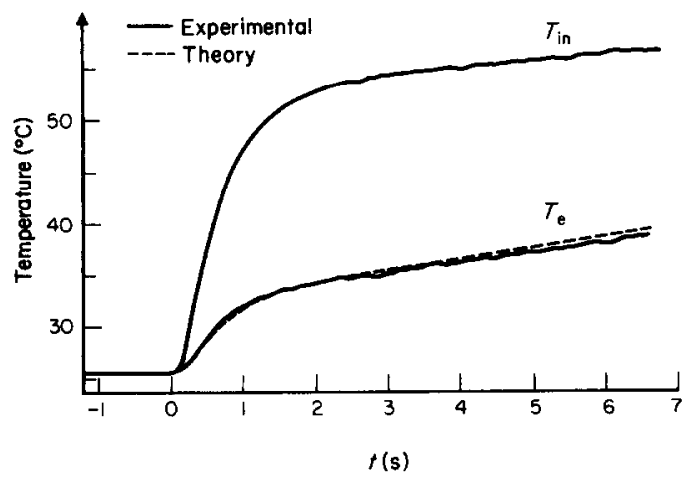

Fig. 1. Recording of inlet and exit fluid temperatures and results of time-domain analysis for $R e=512$ and $R_{t}=3.5$. 
It is also important to note that the time-domain analysis cannot consider the space dependence of the local heat transfer coefficient in a test core.

This paper improves the accuracy of the conventional time-domain analysis and also develops a new Laplace-domain analysis which can consider the space dependence of the local heat transfer coefficient in a heat exchanging device under single-blow testing. Cubic spline polynomials are employed to describe the measured inlet and outlet fluid temperatures. Thus, the methods provide greater flexibility in design of the testing facility, a broader application to any system geometry under any testing conditions, and better accuracy. The application of the methods is demonstrated through the determination of the heat transfer performance in stationary and rotating parallel-disk assemblies.

\section{ANALYSIS}

Consider an incompressible fiuid flowing radially outward through two co-rotating parallel circular disks of spacing $B$. Let $r_{\mathrm{in}}$ and $r_{\mathrm{e}}$ be the inner and outer radii of the disks, respectively. A cylindrical coordinate system $(r, \theta, z)$ is used with the origin fixed at the center between the disks on the axis of rotation. The radial distance from the rotational axis is $r$. Both the fluid and surface temperatures, $T_{\mathrm{f}}$ and $T_{\mathrm{s}}$, respectively, are considered one-dimensional in the $r$-direction and are time dependent, namely $T_{f}(r, t)$ and $T_{\mathrm{s}}(r, t)$. The heat balance leads to the following equations:

disk surface

$$
(\rho c)_{\mathrm{s}} \frac{\partial T_{\mathrm{s}}}{\partial t}=\frac{2 h}{b}\left(T_{\mathrm{f}}-T_{\mathrm{s}}\right)
$$

fluid

$$
(\rho c)_{\mathrm{f}}\left(\frac{\partial T_{\mathrm{f}}}{\partial t}+u \frac{\partial T_{\mathrm{f}}}{\partial r}\right)=\frac{2 h}{B}\left(T_{\mathrm{s}}-T_{\mathrm{f}}\right)
$$

The heat transfer coefficient $h$ may vary with $r$. The appropriate initial and boundary conditions are

$$
\begin{gathered}
T_{\mathrm{s}}(0, r)=T_{\mathrm{r}}(0, r)=0 \\
T_{\mathrm{f}}\left(t, r_{\mathrm{in}}\right)=T_{\mathrm{in}}(t)
\end{gathered}
$$

where the temperature coordinate was shifted so that the initial temperature can be expressed as zero.

Applying the Laplace transformation to equations (1) and (2) with the assumption that $h$ is constant with regard to time and the definition of

$$
x=\pi\left(r^{2}-r_{\mathrm{in}}^{2}\right)
$$

produces [16]

$$
\frac{\bar{T}_{\mathrm{e}}(p)}{\bar{T}_{\mathrm{in}}(p)}=\exp \left[-\frac{p}{a_{\mathrm{f}}} \int_{0}^{x_{\mathrm{c}}}\left(1+\frac{b_{\mathrm{f}} h}{p+b_{\mathrm{s}} h}\right) \mathrm{d} x\right]
$$

Here, $\bar{T}_{e}$ and $\bar{T}_{\mathrm{in}}$ are the Laplace transformed functions of the fluid temperature $T_{f}$ at the exit and inlet, respectively. The dummy variable in the Laplace transformation is represented by $p$ and

$$
a_{\mathrm{r}}=2 \pi r u, \quad b_{\mathrm{s}}=\frac{2}{b(\rho c)_{\mathrm{s}}}, \quad b_{\mathrm{f}}=\frac{2}{B(\rho c)_{\mathrm{r}}} .
$$

Equation (6) is the equation for determining $h$ in convective heat transfer through co-rotating or stationary parallel disks. Two approaches can be followed : time- and Laplace-domain analyses.

\section{Time-domain analysis}

Taking an inverse Laplace transformation of equation (6) results in

$$
T_{\mathrm{e}}(t)=\int_{0}^{t} T_{\mathrm{in}}(t-\tau) M(\tau) \mathrm{d} \tau
$$

in which

$$
M(\tau)=L^{-1}\left\{\exp \left[-\frac{p}{a_{f}} \int_{0}^{x_{s}}\left(1+\frac{b_{\mathrm{f}} h}{p+b_{\mathrm{s}} h}\right) \mathrm{d} x\right]\right\}
$$

In equation (8), $T_{\mathrm{a}}(t)$ and $T_{\text {in }}(t)$ are known through the recordings of the thermocouples installed at the exit and inlet, respectively, while $h(x)$ is the known quantity to be determined. Because of the mathematical difficulty in solving equation (8), $h$ is assumed to be uniform in space, as $h$, whose correct value will be determined by a trial-and-error procedure. Equation (8) can then be written as :

$$
\begin{aligned}
& \text { (i) } 0 \leqslant t \leqslant t^{*} \\
& T_{e}(t)=0 ;
\end{aligned}
$$

(ii) $t \geqslant t^{*}$

$$
\begin{array}{r}
T_{\mathrm{e}}(t)=\exp \left(-\frac{b_{\mathrm{f}} \tilde{h} x_{\mathrm{e}}}{a_{\mathrm{f}}}\right)\left[\int_{0}^{t-t^{*}} T_{\mathrm{in}}\left(t-\tau-t^{*}\right)\right. \\
\quad \times(E / \tau)^{1 / 2} \exp \left(-b_{\mathrm{s}} \tilde{h} \tau\right) I_{\mathrm{i}}\left[2(E \tau)^{1 / 2}\right] \mathrm{d} \tau \\
\left.+T_{\mathrm{in}}\left(t-t^{*}\right)\right]
\end{array}
$$

where $I_{1}$ is the modified Bessel function of the first kind and

$$
t^{*}=x_{\mathrm{e}} / a_{\mathrm{f}} ; \quad E=b_{\mathrm{s}} b_{\mathrm{f}} x_{\mathrm{e}} h^{-2} / a_{\mathrm{f}} .
$$

The advantage of equation (10b) over the previous method [7] is that the Laplace transformation of $T_{\text {in }}$ is not required and $T_{\mathrm{in}}$ can be any arbitrary function of time. In practice, $T_{\text {is }}$ has been forced to be a simple function due to the difficulty in the required Laplace transformation. Therefore, the present method provides a greater flexibility in the construction of the air heating system and a better accuracy in $h$.

In this study, both the inlet and exit fluid temperatures are approximated by cubic spline polynomials [15]. The measured response curves of the inlet and exit fluid temperatures are divided into $n$ time intervals and a cubic spline polynomial is established in each subinterval $t_{i} \leqslant t \leqslant t_{i+1}$ as 


$$
T(t)=\sum_{i=1}^{n} S_{i}(t)\left(a_{i}+b_{i} t+c_{i} t^{2}+d_{i} t^{3}\right)
$$

Here

$$
S_{i}(t)=1 \text { for } t_{i} \leqslant t \leqslant t_{i+1}
$$

where $t_{i}$ and $t_{i+1}$ denote two end points of the $i$ th subinterval, while $a_{i}, b_{i}, c_{i}$ and $d_{i}$ are the coefficients of the polynomials at the $i$ th subinterval.

Under an ideal situation in which the heat transfer coefficient $h$ is uniform with space and time, $\bar{h}$ can be determined from equation (10) by an iterative procedure using any single value on a response curve of $T_{\mathrm{e}}$. However, in reality, $\bar{h}$ may change with space and time. As a result, the value of $h$ differs depending on the selection of a point on the $T_{\mathrm{e}}$ curve. In order to overcome this difficulty an optimum value, $\bar{h}^{*}$, of the heat transfer coefficient $\bar{h}$ is sought which yields a minimum $\sigma$ defined as

$$
\sigma \equiv \frac{\int_{t_{\mathrm{Lt}}}^{\mathrm{r}_{\mathrm{H} t}}\left[T_{\mathrm{em}}(t)-T_{\mathrm{ec}}(t, \bar{h})\right]^{2} \mathrm{~d} t}{\int_{t_{\mathrm{L} t}}^{t_{\mathrm{H} t}} \mathrm{~d} t} .
$$

Here, $t_{\mathrm{H} t}$ and $t_{\mathrm{L} t}$ are the upper and lower time limits, respectively, while $T_{\mathrm{em}}$ and $T_{\mathrm{ec}}$ represent the measured and calculated exit fluid temperatures, respectively.

\section{Laplace-domain analysis}

The Laplace-domain analysis is similar to the timedomain analysis in that the calculated exit temperature is compared to the measured exit temperature to find the system heat transfer coefficient. The comparison, however, is made through the Laplace transformed functions of the two exit temperatures with equation (6) and it enables one to consider the space dependence of the heat transfer coefficient.

As in the time-domain analysis, cubic polynomials are used to approximate the inlet and exit fluid temperatures in equation (6). The Laplace transformation of the polynomial in equation (12) is

$$
\bar{T}(p)=\sum_{i+1}^{n}\left(a_{i} F_{i}^{(1)}+b_{i} F_{i}^{(2)}+c_{i} F_{i}^{(3)}+d_{i} F_{i}^{(4)}\right)
$$

where

$$
F_{i}^{(j)}=\int_{t_{i}}^{t_{i+1}} t^{j-1} \mathrm{e}^{-p t} \mathrm{~d} t
$$

when $i=n, t_{n+1} \rightarrow \infty$.

The right-hand side of equation (6) can be calculated for a given $p$ using equation (15). On the lefthand side, every quantity is known at a given $p$ except $h$. Information on the spatial distribution of $h$ should be prescribed in advance to find the value of the lefthand side of equation (6) or to find the $h$ which satisfies

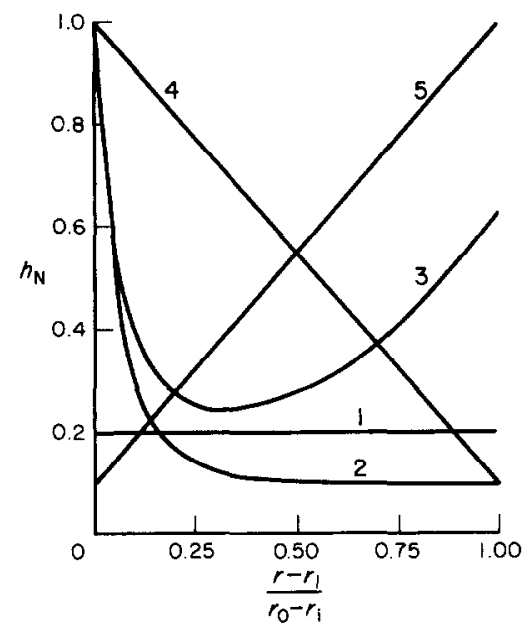

FIG. 2. Spacewise variation of the $h_{\mathrm{N}}$ function tested in the Laplace-domain analysis.

the equation. In this study, $h$ was prescribed in the form

$$
h(x)=g h_{\mathrm{N}}(x)
$$

where $g$ is a scale factor and $h_{\mathrm{N}}(x)$ is an assumed distribution function, which can be chosen from one's experience or results of numerical analysis. Five representative profiles of $h_{\mathrm{N}}(x)$ tested in this study are shown in Fig. 2. The distributions of local heat transfer coefficients (in dimensionless form as local Nusselt numbers) were theoretically studied for laminar [18] and turbulent [19] flow inside parallel disks.

With $h_{\mathrm{N}}(x)$ and $p$ specified, equation (17) is substituted into equation (6) to determine $g$ through an iterative procedure.

The remaining question is how large should the dummy variable $p$ in the Laplace transformation be. A reasonable value of $p$ can be found from the characteristics of the Laplace transformation. The exponential factor, $\exp (-p t)$, in the transformation can be interpreted as a weighting factor. Transformation with a large $p$ puts a larger relative weight on a function in small $t$ and transformation with a small $p$ reduces the weight on the function in small $t$ and increases the weight on large $t$ as shown in Fig. 3. If available data are for the time interval from $t=0$ to $t_{\mathrm{L} p}$, the weighting factor for $t \geqslant t_{\mathrm{L}, p}$ should not be larger than a certain value, say, $w_{L}$. This defines a lower bound of possible $p$ for analysis. If one's interest is on the time interval from $t=0$ to $t_{\mathrm{H} p}$, the weighting factor for $t \leqslant t_{\mathrm{H} p}$ (Fig. 3) should not be smaller than a certain value, say, $w_{\mathrm{H}}$ and defines an upper bound of possible $p$. So, a reasonable choice of $p$ is bounded by

$$
p_{\mathrm{L}}=\frac{-\ln w_{\mathrm{L}}}{t_{\mathrm{L} p}} \leqslant p \leqslant \frac{-\ln w_{\mathrm{H}}}{t_{\mathrm{H} p}}=p_{\mathrm{H}} .
$$

\section{Comparison between Laplace- and time-domain analyses}

The Laplace- and time-domain analyses are related by the definition of Laplace transforms. However, the 


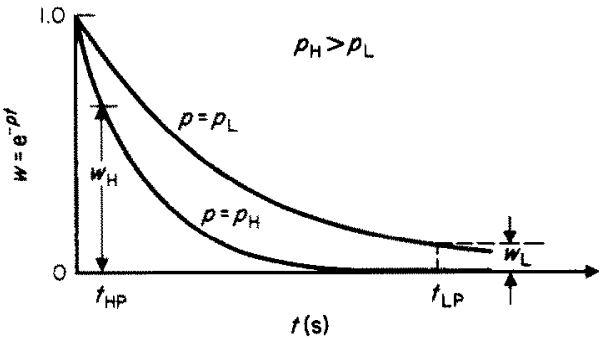

FIG. 3. Graphical illustration of $w=\exp (-p t)$.

former has merits and shortcomings in comparison with the latter. The Laplace-domain analysis permits spacewise variation in the heat transfer coefficient and its results are more accurate than those from the timedomain analysis. The shortcomings of the Laplacedomain analysis include : (a) a need for a longer testing time (for $w_{\mathrm{H}}=0.2$ and $w_{\mathrm{L}}=0.01$, it takes approximately three times longer than that required for the time-domain analysis); (b) less flexibility in the selection of the arbitrary time interval. The Laplacedomain analysis uses a continuous recording of $T_{e}$ from zero time. It cannot skip small times where larger errors are involved due to the steep response of the exit fluid temperature. In contrast, the small-time regime can be excluded in the time-domain analysis by selecting proper $t_{\mathrm{H} t}$ and $t_{\mathrm{L} t}$ to be used in equation (14).

Since the heat transfer coefficient is taken to be uniformly distributed in the time-domain analysis, the Laplace-domain analysis with a flat $h_{\mathrm{N}}(x)$ should produce the same result with the time-domain analysis or vice versa. This point was checked in sample tests with the combinations of $R_{t}=0,3$ and $R e=530$, 1850. The discrepancies between the two analyses were found to be within $4 \%$ in these tests.

\section{TEST APPARATUS}

The test apparatus consisted of a blower, a heating element, a disk assembly and devices for measurement and recording of temperature and velocity of flow as shown in Fig. 4. Air was forced to flow through the heating element by a centrifugal blower which was driven by a G.E. dynamometer. The heating element, consisting of a nichrome wire screen of $100 \times 100$ mesh per square inch with a $0.00787 \mathrm{~cm}$ diameter, was powered from a variable current a.c. welding coil. The heated air in the temperature range of $40-60^{\circ} \mathrm{C}$ was guided into the disk assembly, which consisted of five annular aluminum disks with a $0.5 \mathrm{~mm}$ thickness, an outside diameter of $31 \mathrm{~cm}$ and an inside diameter of $16 \mathrm{~cm}$ installed coaxially and in parallel at a spacing of $0.38 \mathrm{~cm}$. Four spacers of $1 \mathrm{~cm}$ diameter were used between the disks midway between the inner radius and the outer radius at right angles to each other for uniform spacing of disks. To suppress the vibration of the disks, small pads were installed between the two disks at four different locations in the circumference of the disks. Air flow rate was measured by a pitot tube which was installed upstream of the heating element. The difference between static and stagnation pressure was measured at seven different positions in the channel by traversing with the pitot tube. The pitot tube was connected to a Barocel pressure sensor, type 523-1, and the sensor was connected to a Barocel Electronic manometer, type 1023. The total air fiow rate was calculated by taking an integration of these measurements across the channel, assuming angular symmetry. Temperature was measured at the inlet and at the outlet of the disk assembly by thermocouples of 40 gage copper-constantan. At each place, four pairs of thermocouples were installed in series.

The temperature signal from the thermocouples was amplified by a homemade amplifer based on an LM324N chip and then recorded continuously by a Honeywell model 1406 visicorder. The sequence of actual measurements was: (1) let air flow into the system and then wait until the system reaches a steady state; (2) start recording temperature changes at the inlet and outlet; (3) turn on the heater; (4) keep recording temperatures over a certain interval of time and (5) turn off the power to the heater and the recorder.

An error analysis was conducted to determine the uncertainties in the experimental data by utilizing the method described in ref. [17]. The best estimate of uncertainties were listed under three categories.

(1) Uncertainty in geometric measurement:

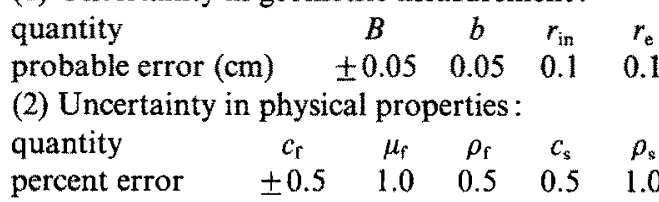

(3) Uncertainty in instrumentation:

$\begin{array}{lcc}\text { quantity } & T_{\mathrm{f}} \text { (steady) } & T_{\mathrm{f}} \text { (transient) } \\ \text { probable error }(\mathrm{K}) & \pm 0.1 & 0.2\end{array}$

The uncertainty in $\mathrm{Nu}$ was estimated to be about $8 \%$ at all $R e$ tested.

\section{RESULTS AND DISCUSSION}

Experiments were conducted on the disk assembly by varying the through-flow Reynolds number $R e$ between 500 and 4000 and the rotation number $R_{t}$ from 0 to 3.5. The average heat transfer coefficient $\bar{h}$ was determined by both the improved Laplace- and time-domain analyses and was expressed in dimensionless form as the average Nusselt number $\overline{N u}$ in Figs. 5 and 6.

Figure 5 shows the effects of the assumed profile of the heat transfer coefficient $h_{\mathrm{N}}(x)$ and the $p$ chosen on the calculated value of the heat transfer coefficient. The top abscissa is the $p$ coordinate, while the middle and the bottom abscissas are the time coordinates which indicate the time when the magnitude of the weighting factor $w=\exp (-p t)$ becomes 0.2 and 0.01 , respectively, at the corresponding $p$. If $w_{H}$ and $w_{L}$ are taken to be 0.2 and 0.01 , respectively, the middle 


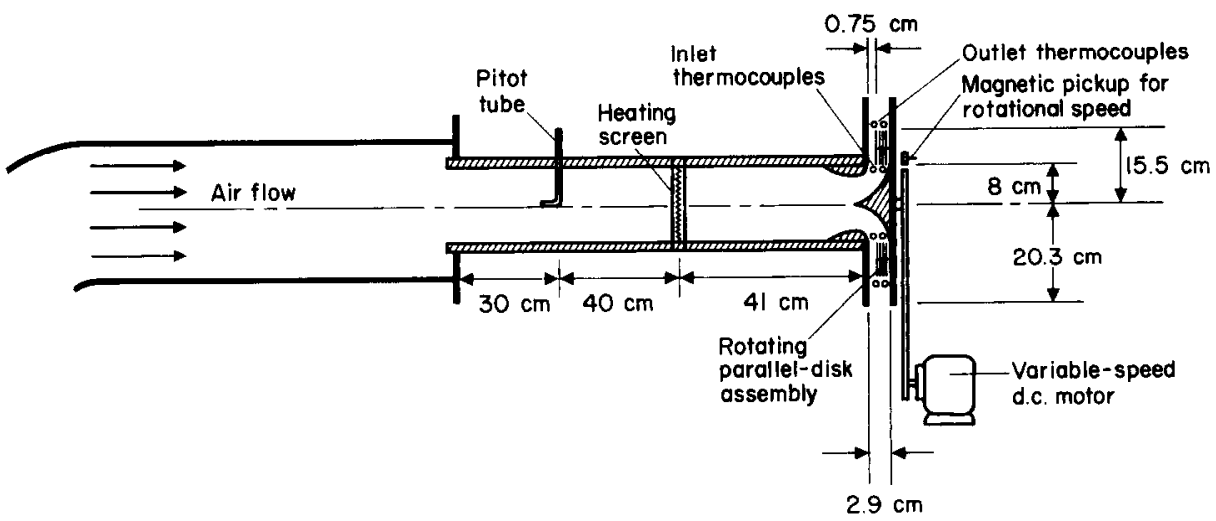

FIG. 4. A schematic diagram of the test apparatus.

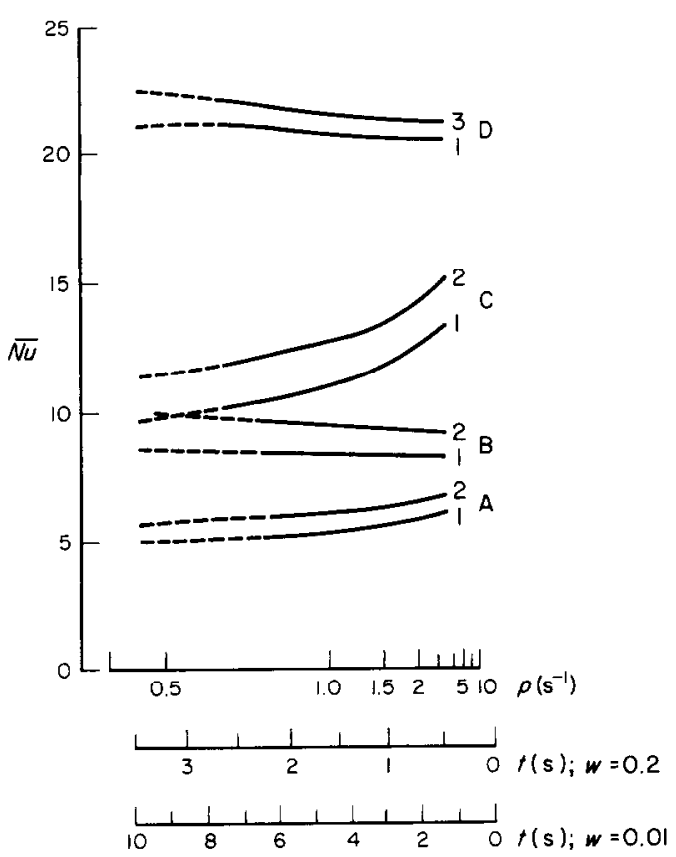

FIG. 5. Average Nusselt number obtained by the Laplacedomain analysis for: (A) $R e=519, R_{t}=0$; (B) $R e=512$, $R_{t}=3.5 ;$ (C) $R e=1810, R_{t}=0$; and (D) $R e=1780, R_{t}=3.4$.

coordinate is interpreted as the coordinate of the $t_{\mathrm{H} p}$ and the bottom coordinate as the coordinate of $t_{\mathrm{L} p}$. The fact that $h$ is a function of time even though it was assumed constant makes the calculated $h$ a function of $p$. Since the calculated $h$ is the $h$ averaged implicitly over the time and in that averaging process the related weighting factor, $\exp (-p t)$, is not constant but a function of $p$ and time as shown in Fig. 3, the calculated $h$ with a larger $p$ is more heavily determined with the $h$ in small times than the $h$ with a smaller $p$. By this reason the curve of $N u$ vs $p$ may be interpreted somewhat loosely, as the curve of $\mathrm{Nu}$ vs time. Cases $A$ and $C$ correspond to stationary disks, while cases $\mathrm{B}$ and $\mathrm{D}$ deal with rotating disks. There are two lower flow cases, $A$ and $B$, and two higher flow cases, $C$ and $D$. The solid lines cover the region of $p$ specified by equation (18). The selected values of $w_{\mathrm{H} p}, w_{\mathrm{L} p}$ and $t_{\mathrm{H} p}$ were $0.2,0.01$ and $1.5 \mathrm{~s}$, respectively. The numbers 1 ,

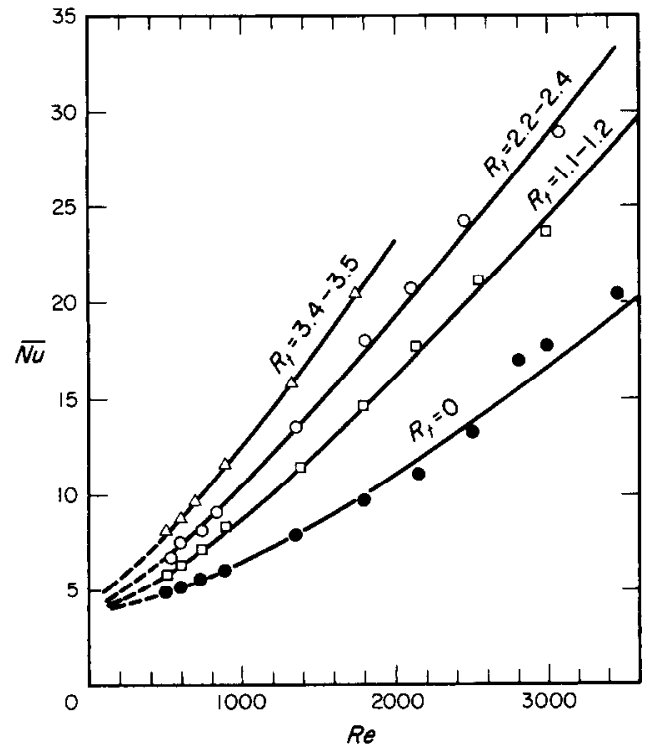

Fic. 6. Average Nusselt number obtained by the timedomain analysis.

2 and 3 identify the corresponding cases in Fig. 2. To check the effect of non-uniformity of $h$, all the distribution curves of $h$ shown in Fig. 2 were tested in each case. The uniform profile in Fig. 2 yielded the lowest values of $h$ or equivalently, $N u$. Profile 2 yielded the highest value except in case $\mathrm{D}$, where a solution to equation (6) was not found. This is an unrealistic profile as the rotation number is high in this case. Profile 3, which is more realistic, produced the highest value. The other profiles, 4 and 5 , resulted in the intermediate value of $\mathrm{Nu}$, not shown in Fig. 5. As verified in this result, the calculated $\mathrm{Nu}$ depends on the profile of the heat transfer coefficient distribution and the level of the dependence is not so small that it can be safely neglected. By inserting the pre-knowledge on the spatial distribution of the heat transfer coefficient through $h_{\mathrm{N}}(x)$, one can increase the evaluation accuracy over the conventional single-blow analyses which assume the distribution is always flat regardless of the system conditions.

Figure 5 also shows the dependence of $\overline{N u}$ on $p$ used 
in the calculation resulting from the time dependence of the heat transfer coefficient. The dependence of $\overline{N u}$ on $p$ is greater in stationary disk systems as observed in cases $\mathrm{A}$ and $\mathrm{C}$ in Fig. 5. It was due to the presence of spacers in the disk assembly which not only broke the uniformity in the angular direction which was assumed in this study but also generated flow recirculation downstream. The recirculation flow is generally unsteady. The effect decreases as the rotation number increases, since the angular motion of the fluid reduces non-uniformity. The effect also decreases as the Reynolds number decreases because of the increase of the viscous effect at a lower Reynolds number. From this discussion it can be said that the dependence of the calculated $\bar{h}$ on $p$ is so small that it can be practically neglected in a system where the heat transfer coefficient is not highly unsteady and that the Laplace-domain analysis is a stable method.

Figure 6 depicts the heat transfer performance obtained by the time-domain analysis as functions of the Reynolds and rotation numbers. It is observed that $N u$ increases with an increase in $R e$ and/or $R_{i}$. Upon extrapolation toward lower values of $R e$, all curves intersect with the ordinate at a value of $\overline{\mathrm{Nu}}$ (defined based on $B$ rather than $B / 2$ as in ref. [20]) between 3.8 and 4.1 which corresponds to the Nusselt numbers for laminar convective heat transfer in parallel channels having uniform wall temperature and uniform wall heat flux, respectively [20]. The reason for this convergence of $N u$ curves is due to the large diffusion effect of momentum at small Reynolds number flows. In a rotating flow, the heat transfer is influenced by the rotation effect only through the reshaping of the velocity profile of the radial velocity component $u$ and the axial velocity component $v$. The $u-v$ vector field is influenced by the centrifugal force. If the angular velocity component, $w$, is uniform across the channel, the velocity profile $u-v$ is nearly all the same regardless of the value of $w$ at a specified flow rate, because the centrifugal force field from the uniform $w$ is also uniform and its net effect on the, $u$ $v$, vector field disappears. In a low Reynolds number flow, the viscous effect (diffusion) is very large and the diffusion of angular momentum from a rotating disk to a fluid can be so rapid that the profile of the angular velocity component, $w$, is nearly uniform from the wall to the center. The rotation effect on heat transfer is practically zero and the heat transfer rate is the same as the rate of the non-rotating flow at the same low Reynolds number. Consequently, the radial flow and the non-radial flow come to have the same Nusselt number. This is also the reason for the higher rotation effect at a flow of a high Reynolds number.

\section{CONCLUSIONS}

A new Laplace-domain analysis has been developed and the conventional method has been improved for better performance evaluation of heat exchanger units or surfaces by a single-blow technique. The methods are demonstrated by an application to forced convection inside stationary and rotating parallel disks. It is concluded that :

(1) On the Laplace-domain analysis: (i) the negligence of space dependence of heat transfer coefficient in the conventional single-blow techniques may result in errors which cannot be safely neglected in evaluating the average heat transfer coefficient; (ii) the Laplace-domain analysis in this study can consider the space dependence of the heat transfer coefficient of a system; (iii) the inlet fluid temperature is described by a cubic spline polynomial rather than a fixed pattern such as a step or exponential function of time as in the conventional singlc-blow techniques. This results in more flexibility in design of the air heating system and better accuracy in heat transfer evaluation.

(2) On the improved method; the conventional method has been improved in its accuracy and flexibility by : (i) describing the fluid temperatures by cubic spline polynomials; (ii) dispensing the Laplace transformation on the inlet temperature function; (iii) defining a new curve-matching criterion for better fitting of theoretical and experimental exit fluid temperatures.

By applying the methods developed in this study to the rotating disk system it has been discovered that rotation of disks increases the heat transfer rate and the rotation effect is large at a higher Reynolds number.

\section{REFERENCES}

1. P. F. Pucci, C. P. Howard and C. H. Piersall, The single blow transient testing technique for compact heat exchanger surfaces, J. Engng Pwr 89, 2940 (1967).

2. W. M. Kays and A. L. London, Compact Heat Exchangers, 2nd Edn, p. 135. McGraw-Hill, New York (1964).

3. T. E. M. Schumann, Heat transfer: a liquid flowing through a porous prism, J. Franklin Inst. 28, 405-416 (1929).

4. G. L. Lock, Heat transfer and friction characteristics of porous solid, Report No. TR-10, Department of Mechanical Engineering, Stanford University, Stanford, California (1950).

5. C. P. Howard, The single blow problem including the effect of longitudinal conduction, ASME Paper No. 64GT2-11, presented at Gas Turbine Conterence and Product Show, Houston, Texas (1964).

6. J. R. Mondt and D. C. Siegla, Performance of perforated heat exchanger surfaces, J. Engng Pwr 96, 81-86 (1974).

7. G. F. Kohlmayr, Exact maximum slope for transient matrix heat-transfer testing, Int. J. Heat Mass Transfer 9, 671-680 (1966).

8. G. F. Kohlmayr, Analytical solution of the single-blow problem by a double Laplace transform method, J. Heat Transfer 90, 176-178 (1968).

9. G. F. Kohlmayr, Extension of the maximum slope method to arbitrary upstream fluid temperature changes, J. Heat Transfer 90, 130-134 (1968).

10. G. F. Kohlmayr, Properties of the transient heat transfer (single-blow) temperature response functions, A.I.Ch.E. Jl 14, 499-50I (1968). 
11. G. F. Kohlmayr, An indirect curve-matching method for transient matrix heat-transfer testing in the low NTUrange, Ini. J. Heat Mass Transfer 11, 567-581 (1968).

12. C. Y Liang and Wen-Jei Yang, Modified single-blow technique for performance evaluation on heat transfer surfaces, J. Heat Transfer 97, 16-21 (1975).

13. R. S. Mullisen and R. I. Loehrke, A transient heat transfer test for computer-based data reduction, $\Lambda$ SME Paper No. 83-HT-65, presented at the 1983 National Heat Transfer Conference, Seattle, Washington (1983).

14. Y. Wu, M. Li, M. Cai and Z. Cai, The maximum slope technique for an actual inlet fluid temperature change, Proceedings of 1983 ASME-JSME Thermal Engineering Joint Conference, Vol. 3, pp. 113-117 (1983).

15. G. Dahlquist and A. Bjorck, Numerical Methods, p. 132. Prentice-Hall, Englewood Cliffs, New Jersey (1974)

16. Y. S. Sim, A numerical and experimental study on the flow and heat transfer characteristics in co-rotating disk systems, Ph.D. Thesis, Mechanical Engineering, University of Michigan, Ann Arbor, Michigan, pp. 76-77 (1983).

17. S. J. Kline and F. A. McClintock, Describing uncertainty in single sample experiments, Mech. Engng 75, 3-8 (1953).

18. Y. S. Sim and Wen-Jei Yang, Numerical study on heat transfer in laminary flow through co-rotating parallel disks, Int. J. Heat Mass Transfer 27, 1963-1970 (1984).

19. Y. S. Sim and Wen-Jei Yang. Turbulent heat transfer in co-rotating annual disks, Num. Heat Transfer 8, 299 $316(1985)$.

20. W. M. Rohsenow and H. Y. Choi, Heat, Mass and Momentum Transfer. Prentice-Hall, Englewood Cliff, New Jersey (1961).

\section{NOUVELLES ANALYSES D'EVALUATION DE PERFORMANCE SUR LES SURFACES CONVECTANTES PAR LA TECHNIQUE DU SOUFFLAGE UNIQUE}

Résumé-On présente une méthode qui peut considérer la dépendance spatiale du coefficient de transfert thermique sur les échangeurs de chaleur ou sur les surfaces, en évaluant la performance du transfert thermique d'un système par la technique du soufflage unique. L'analyse d'évaluation de performance est conduite dans le domaine de la transformée de Laplace. On utilise les polynômes splines cubiques pour représenter les températures du fluide à l'entrée et à la sortie. La méthode d'analyse conventionnelle est améliorée à travers une modélisation mathématique modifiée pour une meilleure précision. Les méthodes sont appliquées à l'évaluation de la performance thermique dans des ensembles de disques parallèles stationnaires et tournants.

\section{EIN NEUARTIGES VERFAHREN ZUR LEISTUNGSBESTIMMUNG AN WÄRMETAUSCHEROBERFLÄCHEN MIT DER "SINGLE-BLOW"-METHODE}

Zusammenfassung--Die Abhandlung stellt ein Verfahren vor, welches die örtliche Abhängigkeit des Wärmeübergangskoeffizienten in Wärmetauschern bei der Bestimmung der Übertragungsleistung eines Systems mit Hilfe der "single-blow"-Methode berücksichtigt. Die Leistungsbestimmung wird im Laplace-transformierten Bereich durchgeführl. Zur Anpassung an die gemessenen Ein- und Austrittstemperaturen werden kubische Spline-Funktionen verwendet. Außerdem wird die herkömmliche Berechnungsmethode durch ein modifiziertes mathematisches Modell verbessert. Die Methoden werden zur Bestimmung des

Wärmeübertragungsverhaltens an stillstehenden und rotierenden Plattenwärmetauschern verwendet.

\section{НОВЫЙ АНАЛИЗ ОЦЕНКИ К.П.Д. ТЕПЛООБМЕННЫХ ПОВЕРХНОСТЕИ МЕТОДОМ ОДИНОЧНОГО ВДУВА}

Аннотация-Предложен метод изучения пространственной зависимости коэффициента теплообмена узлов и поверхностей при оценке к.п.д. теплопередачи системы методом одиночного вдува. Анализ проводится в пространстве изображений по Лапласу. Измеренные температуры жидкости на входе и выходе аппроксимировались кубическии сплайнами. Для получения более высокой точности общепринятый метод улучшен с помощью математического моделирования. Метод применяется для оченки к.п.д. теплопередачи в устройствах с неподвижными и вращаюшимися параллельными дискамн. 